\title{
Mothers of children with Tourette's syndrome
}

ABSTRACT: Rita Khoury, Mothers of children with Tourette's syndrome. Interdisciplinary Contexts of Special Pedagogy, No. 19, Poznań 2017. Pp. 171-199. Adam Mickiewicz University Press. ISSN 2300-391X

The purpose of this study was to gather data from the mothers of children with Tourette Syndrome (TS), in order to examine the extent to which the existence of a child with TS in the family affected mothers' Quality of Life (QOL). The research was conducted according to the qualitative methods. Data was collected from semistructures interviews with 50 mothers of children with TS. The interviews were analyzed using a content analysis method. Conclusions derived from the research findings found that lack of accurate diagnosis and information leaded mothers to a state of imbalance and great stress. When they were given accurate information, they seemed to be more able to advocate for the child with TS and thus prevent misunderstandings, and consequent unpleasant situations and confusion.

KEY WORDS: Mothers, Quality of Life, Tourette syndrome.

\section{Introduction}

Tourette syndrome is a neuropsychiatric disorder named after Dr. Georges Gilles de la Tourette (1857-1904). It is an inherited, neurological disorder characterized by repeated involuntary movements and uncontrollable vocal (phonic) sounds called tics. Most tics occur at the level of the shoulders and above: eye tics were the most frequent, followed by facial/cervical tics, and those involving 
the arms and legs ${ }^{1}$. In some cases, such tics can include inappropriate words and phrases 2 . The symptoms of TS generally appear before the individual is 18 years old and usually at the age of six to seven years old ${ }^{3}$. TS can affect people of all ethnic groups, and it appears to be familial (i.e. it 'runs' in families). Recent information appears to indicate that there is likely to be a significant genetic factor responsible for its genesis. Research by Abelson et al. ${ }^{4}$, reviewed some of the genetic research and identified a new candidate gene. Gender is also linked to the incidence of TS: boys are significantly more likely to develop TS than girls; males are affected three to four times more than females ${ }^{5}$. Most people with TS experience additional problems such as Obsessive-Compulsive Disorder (OCD) ${ }^{6}$. Additional problems may include Attention Deficit Hyperactivity Disorder (ADHD) or Attention Deficit Disorder (ADD)7; learning disabilities (LD), which include reading, writing, arithmetic, and perceptual difficulties; problems with impulse control, which can result in overly aggressive behavior and socially inappropriate acts; or sleep disorders, which include frequent awakenings or talking in one's sleep $^{8}$. Study examined the association between tic suppres-

${ }^{1}$ C. Ganos, J. Bongert, L. Asmuss, et al., The Somatotopy Of Tic Inhibition: Where and How Much? Mov Disord. 2015, 5(9), p. 1184-1189.

2 N. Dreher, What is Tourette Syndrome? Current Health, 1997, 23, p. 21.

3 Ibidem, p. 21, J.F Abelson et al., Sequence Variants in Slitrk1 are Associated with Tourette's Syndrome, Science, 2005, 310(5746), p. 317-320, J. Swain, L. Scahill, P. Lombroso, R. King, J. Leckman, Tourette Syndrome and Tic Disorders: A Decade of Progress. Journal of the American Academy of Child and Adolescent Psychiatry, 2007, 46(8), p. 947-968.

4 J.F. Abelson et al., (2005). Sequence Variants in Slitrk1 are Associated with Tourette's Syndrome, Science, 2005, 310, (5746), p. 317-320.

${ }^{5}$ N. Dreher, What is Tourette Syndrome? Current Health, 1997, 23, p. 21, J.F. Abelson et al., (2005). Sequence Variants in Slitrk1 are Associated with Tourette's Syndrome, Science, 2005, 310(5746), p. 317-320.

${ }^{6} \mathrm{M}$. Robertson, Tourette Syndrome, Associated Conditions and the Complexity of Treatment. Brain, 2002, 123, p. 425-462.

7 Ibidem, p. 425-462.

8 R.L. Albin, J.W. Mink, Recent Advances in TS research. Trends Neuroscience, 2006, 293, p. 175-182. 
sion and quality of life. Although most tic patients frequently try to suppress tics, they find suppressing them uncomfortable and distracting. However, those patients who are more satisfied with their ability to suppress their tics also report a higher quality of life?

Having a child with Tourette Syndrome (TS) seriously challenges parents who aspire to raise a 'normal' family, because of the stresses and strains engendered by the unusual behavior of the child with TS10. As mentioned above, children with TS may experience a wide range of psychological, behavioral and psychiatric problems in addition to vocal and motor tics. These difficulties also lead to interpersonal communication problems, feelings of anxiety and mood-changes, and may be accompanied by difficulty in concentrating, hyperactivity and obsessive behaviors ${ }^{11}$. These children usually find it hard to adapt their behavior to their environment and their particular characteristics may have a negative impact on the child's functioning at school. In addition to their difficulties in daily functioning in school, children with TS exhibit significant problems with labile emotions, impulsivity, and aggression directed at others ${ }^{12}$. Usually, this situation engenders confusion, helplessness and sometimes an inability to maintain 'normal' family life.

Parents' perceptions on the nature of a disability are determined to some degree, in line with their cultural values. This is also true for their views about the nature of a disability. Common perceptions include envisaging that their children as developing normally,

${ }^{9}$ N. Matsuda et al., Self-Initiated Coping with Tourette's Syndrome: Effect of Tic Suppression on QOL. Brain Development, 2016, 38(2), p. 233-41.

${ }^{10}$ R.W. Greene (1996). The explosive child: A new approach for understanding and parenting easily frustrated chronically inflexible children. New York, NY, 1997. Available from the Tourette Syndrome Association, Inc. 42-40 Bell Blvd., Suite 205 Bayside, NY, 11361-2820.

${ }^{11}$ D.A. Carter et al., Social and Emotional Adjustment in Children Affected with Gilles De La Tourette's Syndrome: Associations with ADHD and Family Functioning. Journal of Child Psychology and Psychiatry and Allied Disciplines, 2000, 41, p. 215-223.

12 J. Piacentini, R.L. Bergman, M. Keller, J.T. McCracken, Functional Impairment in Children and Adolescents with Obsessive-Compulsive Disorder. Journal of Child and Adolescent Psychopharmacology, 2003, 13, Supplement 1, p. 61-69. 
identifying their children's condition as a temporary or passing condition, and perceiving a disability as God's punishment or, conversely, as God's special gift ${ }^{13}$.

Mexican American mothers of children with disabilities believe their child's development to be normal ${ }^{14}$. Some mothers defined their child as having a disability and yet developing normally. Mexican American mothers of children with language disabilities were not concerned about their children's language difficulties. Although they accepted that their children were developing at a different rate, they had expectations that their children would have better communication skills after age three and the mothers believed that as their children grew older, they would 'catch up' with their peers. On the other hand, Mexican American mothers of children with disabilities clearly distinguished between being disabled and being normal. Believing that each child with a disability was unique, they perceived their child's condition as a disability, and not an illness or disease ${ }^{15}$.

Mothers of children with intellectual disabilityexperience more depression than those of children who develop normally ${ }^{16}$. When the parental experience was examined across diagnoses, differences were noted. Parents of children with Down syndrome have been found to experience less stress, ${ }^{17}$ depression, ${ }^{18}$ than parents of children with other diagnoses, particularly autism. Parents of children with disabilities were found to have poorer parenting efficacy and

13 S.B. Garcia, A.M. Perez, A.A. Ortiz, Mexican-American Mothers' Beliefs about Disabilities: Implications for Early Childhood Intervention. Remedial and Special Education, 2000, 21, p. 90-102.

14 Ibidem, p. 90-102.

15 Ibidem, p. 90-102.

${ }^{16}$ M.B. Olsson, C.P. Hwang, Depression in Mothers and Fathers of Children with Intellectual Disability. Journal of Intellectual Disability Research, 2001, 45, p. 535-543.

${ }^{17}$ L.A. Ricci, R.M. Hodapp, Fathers of Children with Down's Syndrome Versus Other Types of Intellectual Disability: Perceptions, Stress, and Involvement. Journal of Intellectual Disability Research, 2003, 47, p. 273-284.

${ }^{18}$ L. Abbeduto et al., Psychological Well-Being and Coping in Mothers of Youths with Autism, Down Syndrome, or Fragile X Syndrome. American Journal on Mental Retardation, 2004, 109, p. 237-254. 
poorer parental mental health ${ }^{19}$, and poorer marital adjustment. seems that since Down syndrome can be diagnosed either during pregnancy or at birth, rather than at an older age - as is the case of TS, which is diagnosed at the age of 6-7; this can explain the differences in parents' reactions to their child's disability ${ }^{20}$.

Studies regarding the impact of the birth of a child with TS on the family life pattern ${ }^{21}$ found two central aspects regarding the processes that occur in the family of a child diagnosed with TS: 1) the various stages of the parents' responses; 2) consequences for siblings of the child. The model offered by Wanlass and Fortier ${ }^{22}$, which describes the passage of the family of the child with disability through a number of stages from the time of discovery of the disability, reflects similar stages noticed in families of a child with TS, but with a unique emphasis on the syndrome itself and its attributes. The stages indicated are: 'clash', 'denial' and 'sadness', 'focus on the external world' and eventually 'acceptance' 23 .

According to this multi-stage model, the Clash Stage is characterised by shock, mourning and fear Haerle 24 developed a seven-stage model of coping with TS) argues that the initial response of many parents to a diagnosis of TS in their children is 'shock'. This response is very common, particularly in cases in which the syndrome appears suddenly, or when parents had not perceived their child's disability as so severe. Nevertheless, even when parents did sense

${ }^{19}$ J. Kersh, T.T. Hedvat, P. Hauser-Cram, M.E. Warfield, The Contribution of Marital Quality to The Well-Being of Parents of Children with Developmental Disabilities. Journal of Intellectual Disability Research, 2006, 50, p. 883-893.

20 Ibidem, p. 883-893.

${ }^{21}$ A. Duvdevani, M. Hovav, A. Rimmerman, A. Ramot, Parenting and developmental disability in Israel, Jerusalem, 1997.

22 R.L. Wanless, L.M. Fortier, Family Crisis Following the Diagnosis of a Handicapped Child, [in:] Parenting and developmental disability in Israel, eds. A. Duvdevani, M. Hovav, A. Rimmerman \& A. Ramot, Parenting and developmental disability in Israel. Jerusalem: Y.L. Magness Pres, 1997.

23 A. Duvdevani, M. Hovav, A. Rimmerman, A. Ramot, Parenting and developmental disability in Israel, Jerusalem, 1997.

24 T. Haerle, ed., Children with TS: A parent's guide. Rockville, MD, 1992. 
that something was not right for many years previously, hearing the words 'TS' often causes feelings of shock. TS, unlike many other chronic disorders, is a syndrome that is not well known to many people and therefore most parents have difficulty understanding the nature of their child's disorder. A lack of sensation which often arises as a result of discovering that the child has TS, may help parents avoid being swallowed up by feelings of distress and sadness ${ }^{25}$. It also apparently prevents parents from accepting the full meaning of the syndrome and its attributes. At this stage, parents have difficulty absorbing new information provided to them, and therefore during this stage, many neurologists tend to transmit test results and information in a short and simple fashion ${ }^{26}$.

In contrast to these responses of shock, sometimes, as a result of the unique nature of development of the syndrome, the initial response of parents to discovering their children's condition is a sense of profound 'relief'27. Because of the unique characteristics of the syndrome, parents have often been aware that something was not right with their child, for many years before diagnosis ${ }^{28}$. Since, in most cases, TS is not diagnosed until the child is seven to eight years old; this means that parents have often already become concerned about the child's early development before they approach a neurologist, they become worried that something is not right and consequently the eventual diagnosis of TS may be less menacing than their most terrible imagining ${ }^{29}$.

Thus, raising a child with TS has significant implications for the family's everyday life. Like other families who deal with a child with a disability, families of children with TS also undergo crises

${ }^{25}$ M.M. Robertson, M.R. Trimble, A.J. Lees, The Psychopathology of the Gilles De La Tourette Syndrome. British Journal of Psychiatry, 1988, 152, pp. 383-390.

${ }^{26}$ W. Pavot, E. Diener, E., Review of Satisfaction with Life. Psychological Assessment, 1993, 5(2), p. 164-172.

27 E.F. Shimberg, Living with Tourette Syndrome. N.Y., 1995.

28 W. Pavot, E. Diener, Review of Satisfaction with Life. Psychological Assessment, 1993, 5(2), p. 164-172.

${ }^{29}$ E.F. Shimberg, Living with Tourette Syndrome. N.Y., 1995. 
and changes in various areas of family life. Those changes may appear in the family when viewed as an organization and a system, changes in systems of relations between parents and children and also within the parental relationship. Studies indicate that the family is an important mediating factor in the emotional and social adjustment of the child. For this reason, information regarding the manner in which parents and siblings of children with TS tend to respond to this crisis situation and their coping strategies can help professionals in the mental health field, as well as the doctors and neurologists who may encounter such families in the future. It can also help the families, especially the mothers, to better understand how the birth of a child with TS affects the family, and help them learn better ways of dealing with the many difficulties that arise while raising a child with TS together with their other children in the family. The next section discusses conceptions of QOL in relation to mothers who have a child with TS.

Any discussion of QOL usually refers to how 'good' life is. If human beings are seen as organisms with 'potential', capable of mental and social self-realization, then the purpose of life is the ability to allow this 'potential' to develop in both an individual and ecological context. Therefore, QOL, or in other words, 'a good life', means the ability to maximize life's 'potential' in a particular social and ecological context.

QOL is shaped by a variety of life conditions that interact in complex ways. What is considered to be a 'good' life is different for different people. People in various parts of the world have defined quality in their lives in rather distinct ways. Different groups and individuals often think of QOL in ways that are specific to their own life situations and their own characteristics. But a slightly more profound examination of this issue reveals that it is not always a simple task to determine how 'good' life is or what the meaning or purpose of life is. QOL relates to the person's general expectations of life, therefore, its conceptualization varies according to individual perceptions ${ }^{30}$.

30 I. Brown et al., FQOL: Canadian Results from an International Study. Journal of Developmental and Physical Disabilities, 2003, 153, p. 209-230. 
In many cases, QOL relates to a cognitive judgment regarding satisfaction with life and an affective assessment of emotions and moods. It relates to individuals' overall assessment of their internal experiences, including thoughts, attitudes, motives, dreams, and emotions $^{31}$, and their subjective and intuitive assessment of the quality of their experience as they are able to rationally and responsibly report. QOL may not be explainable solely on the basis of objective situations that the individual experiences, as it is affected by the individual's personal perceptions and attitudes ${ }^{32}$, and therefore, different people will not necessarily assess the same life circumstances in the same way.

From a historical perspective, the definitions of QOL have changed over the last decades, and the term has been defined differently by different researchers. Thus, QOL has been defined as the difference between the hopes and expectations of the individual and their present experience 33 , while others see QOL as a sense of personal satisfaction that is more than contentment and happiness but less than fulfillment. It is experienced when a person's basic needs are met and when he or she has the opportunity to pursue and achieve goals in definitive life settings, namely, work, school, home, and community 34 .

Although QOL is defined in different ways, researchers have agreed on two fundamental concepts: QOL is multi-dimensional, and it includes both subjective and objective dimensions ${ }^{35}$. Thus, in QOL research, a distinction is often made between subjective and objective ${ }^{36}$.

${ }^{31}$ E. Diener, R.E. Lucas, Personality and Subjective Wellbeing, [in:] Hedonic psychology: Scientific perspectives on enjoyment. Suffering and well-being. Eds D. Kahneman, E. Diener, N. Schearz, New York 1997.

32 Ibidem.

${ }^{33}$ K.C. Calman, Quality of Life in Cancer Patients: An Hypothesis. Journal of Medical Ethics, 1984, 10, p. 124- 127.

34 Ibidem, p.124- 127.

35 A.S. Halpern, Quality of Life and Conceptual Framework for Evaluating Transition Outcomes. Exceptional Children, 1993, 596, pp. 486-498.

${ }^{36}$ Quality of Life Research Unit, An overview of the Quality of Life Research Unit, University of Toronto. Department of Occupational Therapy Centre for Function and Well-Being, University of Toronto., 2001, Available at: http:/ /www.utoronto.ca/qol / unit.htm (accessed: 1.6.2010). 
Subjective QOL is about feeling good and being satisfied with things in general. Objective QOL is about fulfilling the societal and cultural demands for material wealth, social status and physical well-being.

QOL is also the degree to which people enjoy the important possibilities in their lives ${ }^{37}$. Possibilities result from the opportunities and limitations that people are offered in their lives and reflect the interaction of personal and environmental factors. QOL includes, but is not limited to, the social, physical and emotional functioning of the child and the adolescent, and when indicated, the family members, and it necessarily alters according to changes that occur throughout the child's development. QOL is measured by the difference, at a particular period of time, between the hopes and expectations of the individual and the individual's present experience. It is influenced by the individual's past experience, present lifestyle and personal hopes and ambitions for the future ${ }^{38}$.

As mentioned earlier, this research seeks to explore the QOL of mothers who have a child with TS, with the hope that this exploration and the insights gained from this process might inform best practice and assist policy makers who treat and determine policy for these families especially the mothers.

\section{The conceptual framework of this research}

Systems Theory and the Ecological Model were selected to explain how mothers of children with TS operates and functions in the family. Systems Theory was the name used by early investigators to describe the organization and interdependence of relationships ${ }^{39}$,

${ }^{37}$ H. Ouellette-Kuntz, B. McCreary, Quality of Life Assessment for Persons with Severe Developmental Disabilities. [in] Quality of Life in Health Promotion and Rehabilitation. eds. R. Renwick, I. Brown \& M. Nagler Thousand Oaks, CA, 1996, p. 268-278.

38 K.C. Calman, Quality of Life in Cancer Patients: An Hypothesis. Journal of Medical Ethics, 1984, 10, p. 124-127.

${ }^{39}$ R. Rapoport, R.N. Rapoport, The Dual Career Family: A Variant Pattern and Social Change. Human Relations, 1969, 22(1), pp. 3-30. 
and was defined as a set of objects or elements in interaction to achieve a specific goal ${ }^{40}$. Systems theory considers the way relationships within the family and between the family and the social environment influence individual development and family functioning, and provides guiding principles for family systems ${ }^{41}$. Thus, Systems Theory explains how family members interact and what personal and interpersonal processes occur inside the family.

The Ecological Model views human development from a person-in-environment context, and emphasizes the reciprocal connections between the person and the environment ${ }^{42}$. Thus, the ecological model delineates how mothers interact with the environment outside the family. Use of the two theories (Systems Theory and the Ecological Model) enables a holistic depiction of the mother functioning inside and outside the family system.

\section{Methodology}

Since the research sought to examine the QOL of mothers who have a child with TS, and with no pre-determined hypotheses available, a qualitative approach ${ }^{43}$ was used to address related issues and deepen the understanding of the mothers' perceptions of their QOL. Interviews were conducted with the mothers to ascertain their views, opinions, and feelings ${ }^{44}$.

40 S.D. Ryan, M.S. Gates, Inclusion of Social Subsystem Issues in IT Investment Decisions: An Empirical Assessment. Information Resources Management Journal, 2004, 17(1), p. 1-18.

${ }^{41}$ M. Bowen, Family Therapy in Clinical Practice. Northvale, NJ, 1978.

42 K. Kreppner, R. Lerner, Family systems and the Life Span Development: Issues and Perspectives. [in] Family Systems and Life-Span Development, eds. K. Kreppner, R. Lerner, Hillsdale, New Jersey 1989.

43 Daniel Ortiz, Jennifer Greene, Research Design: Qualitative, Quantitative and Mixed Methods Approaches Book Review on line. Qualitative Research Journal, 2007, 6(2), p. 205-207.

${ }^{44}$ A. Oppenheim, Questionnaire Design, Interviewing and Attitude Measurement, London 1992. 
The research interview was a recorded, open interview that was conducted with the mothers of children with TS. The interviewer presented one initial descriptive question aimed at eliciting as much information as possible: 'Describe what it is like to live with a child with TS at home'. A single open question was used so that the researcher could provide the mothers with the opportunity to continue to develop the discussion as they desired, and to indicate what they felt was important, without any intervention or direction on the part of the researcher. The goal was to understand their personal experience as they felt it and the meaning that they attributed to this experience. Both the researcher and the mothers contributed to and were affected by this process of re-constructing reality ${ }^{45}$. This allowed better and deeper understanding of the impact that the child with TS has on the QOL of the mothers.

The research population included 50 mothers in Israel at the time of the research that had a child with TS living in the family home, who were registered with the TS Organisation in Israel (TSOI). The participants were identified with the help of the TSOI. The TSOI staff mailed letters to the mothers requesting their agreement to participate in the research. All the mothers who agreed to participate in the research were included as participants (50 mothers). At this stage, it is noted that the mothers who consented to participate in the research were homogenous in ethnic origin although the population from which they were drawn (all those families registered with the TSOI) is not so homogenous from this aspect.

\section{Findings and discussion}

In accordance with the research programme, data were gathered from interviews of mothers who have children with TS. Fifty interviews were conducted and recorded in the families' homes. The aim of these interviews was to capture the perceptions and feelings of

\footnotetext{
${ }^{45}$ Ibidem.
} 
mothers regarding their experiences in raising a child with TS, in order to understand their QOL more deeply and how they coped with raising a child having TS on a daily basis. This chapter presents the findings that emerged from the content analysis of the interviews with those mothers.

The fact that a family has a child with TS affects family dynamics and relationships among the mothers and family members. Even though positive relationships between and among family members are very necessary for a good QOL, for some mothers, their relationships apparently undergo significant changes because of the pressure they experience: 'The many pressures i faced made my life impossible'.

For some mothers, they expressed that dealing with the situation caused almost total dissolution of the family:

The stress of our lives tore my husband and me apart, not an uncommon story in the life of a child with TS. We could not understand and we needed guidance to go through all this. We couldn't function as a family.

When the father could not function, and separated himself from the situation, this could cause much frustration the mother:

My husband detached himself... it was his way of coping with the new situation. He didn't want to talk and couldn't help and I felt frustrated.

And when the entire burden fell on the mother, it caused a lot of tension:

As if the family almost disintegrated. There were a lot of problems. In the house my husband and I are very close to one another, we have a very good relationship, but we were so tense and the tension was so hard on me. These were the nights that I cried and cried and my husband couldn't help.

Most of the mothers indicated that they needed guidance and some activities to maintain good relationships within the family: 
I wanted to talk to my husband but I didn't know how to do so, I wish I could get some help.

Families expressed a need to share their feelings in order to function in daily life, as one mother said:

At first my husband and I had difficult times. We did not know what to do, and this created tension between us. But now I feel that it brought us closer. My husband also has TS. We found it out only after we understood that our son has Toilette. Now we speak about it between us a lot and it helps us and makes us closer.

One of the mothers said:

It was most difficult for me because all the time, almost all the time, it was only me who was with him [the child with TS], I slept with him on the couch, because there was a period when he tried to bite himself all the time, he would cause himself injury with his teeth, and I would perform reflexology, and that calmed him down, and I would lie with him on the couch, and I would caress him until he fell asleep. Those were the nights we slept on the couch. In the morning, I was tired and could not function and take care of the other family members.

When a parent could not function, stress was apparently engendered, 'I wanted to talk to my husband but I didn't know how to do so, I wish I could get some help.'

Good cooperation between the parents seemed to help alleviate pressure:

Twice a week I go to exercise class and yoga and my husband puts the children to bed. It also helps. I am with myself and it is very important to me, and I relax from the stresses of the day.

Thus, according to the evidence it seems that when the father isolates himself, the mother apparently takes the responsibility for the care of the child with TS. Sharing feelings and open discussions apparently help to decrease stress. It seems also that Information about TS might help the mothers deal with the situation in a better way, yet this will not necessarily remove all social difficulties. 
My son did not invite his friends to his home because he did not want his friends to see his sister, because he thought he would get teased.

In another case a brother's inability to communicate with the sibling with TS led the brother to isolate himself in his room:

The most difficult episode was when his brother tried to create contact and speak to him [the child with TS]; he would repeat the words that his brother said and would not stop. It annoyed his brother and sometimes he would get so angry that he shut himself in his room.

Some siblings of children with TS showed concern regarding the future of their TS siblings. One of the brothers was afraid that his brother was going to die. When his mother asked him why he felt so, he answered:

Because at first you would go off and discuss with my father, my brother's situation in whispers, and no one told me anything, which caused me to think that something horrible was about to happen.

Siblings apparently do not understand that there are so many problems to deal with and it seems to be difficult for them to accept the fact that the child with TS needs more care.

Thus, it seems that open communication within the family initiated and guided by the mother helped to clarify the feelings of the siblings of the child with TS, and helped the family to understand the needs of all family members.

Thus too, from the evidence gathered from the interviews it appears that there are two critical elements for mothers QOL: The role of the mother within family interaction and provision of accurate and relevant information. And, it seems that openness, and airing and sharing of family members' feelings guided by the mothers, can positively affect the mothers QOL.

Taking care of a child with TS was perceived as an opportunity to do good deeds and thus gain innate satisfaction from helping the child and the family. The findings seem to indicate that in families of children with TS, in order to maintain a 'normal' family interac- 
tion, family members need to talk with each other about their feelings and the ways they are dealing with the situation.

This apparently enables them to feel competent and comfortable. They need to talk about their feelings of safety and fear, and what it takes to improve the sense of security in the family. The mothers' interviews revealed that when they were able to talk openly with each other this helped to prevent stress and generate options for problem solving.

Thus, in sum, the evidence seems to indicate that the mother emerges as a critical figure within the family as a catalyst creating an atmosphere of openness, sharing and airing of feelings, and helping to improve the morale and mood of the family.

It is common assumption that mothers expect to have a perfect, healthy child. Disappointment can be acute when one has a child with TS. mothers may experience feelings of denial, anxiety, guilt, depression, or even anger when they are unable to help their child. One mother said:

After he [child with TS] was expelled from school in Year 9, he spoke about the fact that he had been considering suicide and all kinds of things, and I felt hopeless. How can I make him happy again? Whenever I remember that feeling, I cry. I cried and simply asked the doctor to help me, to find a way for my child to be happy. I had no one to turn to .... and the doctor did not know how to help.

The fact that mothers needed to watch their child all the time exhausted them:

I always had to watch him to ensure that he wouldn't go into the bathroom alone, so $i$ had to go in with him and make sure he wouldn't put his hands in'.

I had to prevent him from having the opportunity to be alone and to hurt himself. I would follow him everywhere. It was as though he was hospitalised, and all the time he couldn't leave the house. I had to be with him all the time until he stopped the behaviour once and for all, and every time he had an attack, obsessions, I would give him medication, and then stop when he calmed down. 
The need for continual supervision and worrying about the child with TS and the need for intensive care often meant that the mothers neglected the other children in the family:

He was unable to wash himself, he could not dress himself. I had to do everything. He was not able. He was in such a state that if he spoke to me, you couldn't be sure if you were communicating with him, it was as though you were talking to him and then didn't know if he was receiving what you said. He was in his own world. At the end of the day I was weak and nervous and couldn't help the other children.'

Thus, mothers often felt that they did not invest enough in their other children, and that they could not protect them and this caused them much sorrow:

Attention and energy are too focused on the child with TS, and I feel that I am not sensitive to the other children. I feel that this is not fair, but I do nothing about it.

Others feared that they might lose control of their child with TS, particularly fearing adolescence and fear for the child's future. With tears in her eyes, one mother said that:

I am really afraid that a day will come and I will not be able to catch him and calm him down. I am particularly afraid of adolescence. He will grow up, continue to swear, and I won't be able to control him. This really scares me. Now he is little, but, what is going to happen when he grows up? [Almost choking with tears, the mother continued saying:] Sometimes I am afraid that he will be a criminal, I don't want to even think about it.

Families apparently need to maintain good relations in order to be strong enough and have the strength to help their other children. One mother said:

I try to maintain a strong relationship with my husband and my other children, because this gives me the ability to help my child with TS.

Lack of information about the syndrome sometimes led mothers to act violently: 
At home, he would go crazy and not stop yelling and cursing. Sometimes it would drive me crazy. I would put him in the room and hit him hard and ask him not to come out. I didn't know he couldn't control his behaviour.

Most of the mothers indicated that if they had been given information about the syndrome they would know how to deal with it:

Knowing that my child could not control himself because he has a neurological problem tore me apart, for years I blamed him for his behaviour and punished him I even sometimes used physical force to control him.

It is commonly assumed that parents feel that part of their role is to protect their children and they expect others to support their children in order to improve their quality of services. Mothers indicated that they had to develop good decision-making strategies and advocacy to help their child with TS:

I always feel that I have to speak up with teachers, doctors and specialists to make sure my child gets good care.

They apparently needed the help of professionals to take care of their children's emotional difficulties:

I cried and simply asked the doctor to help me, to find a way for my child to be happy. I had no one to turn.'

They expressed a need to stand up for the child with TS in the environment in order to protect them from the environment:

People don't understand that he has a disorder and look at him strangely. They think he isn't disciplined. I don't have the strength to explain it to everyone, but I know that I have to do so for his sake.

Thus, according to the evidence, the mothers apparently find it difficult to take care of all of their children as they would like to, as an integral part of their parenting, and simultaneously to advocate for and provide intensive care for the child with TS. Mothers seem 
to be forced to cope with their difficulties alone, and in most cases, do not receive any assistance from the extended family.

My parents did not want to help because they thought I didn't know how to raise my children and they weren't able to cope. My mother and father very rarely come to visit us. They claim that I don't know how to educate my children.

My mother in law is an elderly woman so she does not intervene with the TS'.

Friends stopped visiting us, for some the swearing was very difficult so they stopped coming (for a visit)'.

Inability of friends to help and understand also made the mother feel guilty:

One of our friends constantly accused me of giving my son too much medication, and medications are not good. What, doesn't she understand that I have no choice? She used to aggravate me with her comments, so I told her not to come any more. She made me feel guilty.

These circumstances apparently led to the isolation and exclusion of the family:

The feeling that the environment blames me for not knowing how to raise my child and the conclusion that I am not a successful mother is very difficult, in particular, when it comes from the people who are the closest to you.

Some mothers felt that they neglected their children and did not provide sufficient care for the other children in the family:

Sometimes I would take the little sister to therapy at the psychologist because she starting hitting and biting children in kindergarten and this was new behaviour.

Inability of mothers to help and support all the siblings led to much tension:

The children in the family needed a lot of encouragement and I didn't give it to them. Sometime I would hear the brother say that he wanted to kill himself. 
Mothers didn't see the pain of the other siblings because they were so worried about the child with TS:

My daughter once wanted to run away from home. She couldn't deal with him. She couldn't speak to us about it. She felt tension. He bothered her. She couldn't do her homework because of the noise and yelling. He hit her and she couldn't manage and tried to run away. Only later, when we talked about what happened we understood how much she was suffering.

Thus, the evidence seems to indicate that due to the inability of the mothers to provide sufficient care for all the children and the inability of the extended family or friends to understand the difficulty and to assist, the mothers often felt isolated and alone.

Some mothers reported that they did not trust the medical and psychiatric doctors' abilities to diagnose the problem. From their experience and in their opinion, most doctors did not know what was wrong with the child. One of the mothers said:

After I discovered that my child had almost stopped breathing, I decided to look for a more serious doctor who could explain what was going on with my child. Until then, no doctor had been able to tell us what was wrong with the child. Why hadn't anyone told us what the child has... all these problems all these years.

The mothers often did not receive answers from the public health system and were forced to look for a diagnosis in private health care:

I saw that the child was behaving in a strange way. My husband was out of the country, and I decided to look for a more serious doctor than the one I had. I made an appointment with Dr. S. in Zichron Yakov, because until then no one had told me what was wrong with my child.

Most of the mothers who were interviewed indicated that services provided to the child with TS were defective or inadequate especially during the diagnosis. Sometimes the diagnosis of the symptoms was a shock for the families: 
After much suffering, my friend gave me an article to read. She studies psychology and she said she thought that she knew what my child has. The article exactly described the attacks and the ceremonies that he has, I was shocked. How come the doctor did not tell me what my child had? Then I asked the psychiatrist if this is what my son has, and he said he doesn't like to call it by that name, but that is what he has. It's a shame we had to wait so long to know what my son has. I feel a relief knowing that my son has a neurological problem and that his condition has a name.

Mothers turned to doctors for help in crisis situations and received no help:

He talked to me about the fact that he had considered suicide and all kinds of things that he wanted to do to himself, and I felt helpless. How can I help him and restore joy in his life? It is a feeling that I felt remembering that I cried. I simply asked the doctor to help me, as if he could find a way for me to give him back joy in life. The doctor didn't know and didn't help.

Even when mothers asked for answers when the child was at an early age, they were disappointed when the diagnosis was not sufficiently deep or professional:

At age 4 we went to a psychiatrist because he had temper tantrums, he would yell, he didn't stop repeating words over and over. The doctors diagnosed ADD and recommended Ritalin.

Lack of appropriate information or contradictory information apparently confused the mothers:

One psychologist recommended that I should leave him [the child with TS] alone and not tell him to stop all the time because he could not control his behaviour. But the other psychologist said we have to set limits and teach him that it isn't nice to act this way, and with time he'd learn to control himself.

Mothers reported that if the diagnosis had been given to them earlier, it would have averted unnecessary stress and tension. This 
response was common among the families participating in the research. For example, one mother explained:

The knowledge that my child's disorder had a name and that they knew what was causing the behaviour led me to understand that both I and my son had done nothing wrong. It helped me to accept the fact that my son simply couldn't control his tics. Now I can tell people that my child has a neurological problem.

\section{Another mother said that:}

Knowing that my son's condition has a name brought some relief as we understood that there is situation here that needs to be treated, and it has nothing to do with the fact that we are or are not good parents. Knowing brought some relief.

In another family, the mother said:

When the psychiatrist said, your child has TS, I became dizzy. For years we had run from one doctor to another doctor and no one was able to explain what was wrong with my child.

The discovery (diagnosis) of TS and the acceptance of the diagnosis are difficult, and in many cases, it takes much time until the family receives assistance. The lack of appropriate services was repeatedly noted in the interviews as something that affected the mothers' QOL. Another claim that was made was that if the child could receive appropriate services, daily coping would be ameliorated and less complex. Mothers began to disintegrate when they were not able to diagnose the child's behaviour: 'it was as if the family almost fell apart.' The risk of family breakdown was especially noted during the initial period following diagnosis of the syndrome.

Thus, most of the mothers reported that the medical, psychological and psychiatric care that they received fell far below their needs. These services cost money, and the families with little means were unable to withstand the high expense. Often, the family's decision was to accept services from their medical insurance funds, but 
they sometimes felt that these did not satisfy their needs. In certain cases, out of despair, some families decided to privately seek services and to pay the high cost, which forced them to change their financial priorities in the household. Seven of ten of the families who were interviewed had to change their family's financial priorities in order to finance medical services

An additional deficiency in services that the families noted related to the consideration of the child with TS by the education system. Most of the mothers reported that the education system failed to accept their child's situation and lacked knowledge concerning the child's difficulties and the ability to cope with these difficulties:

The difficult problem began in school, in Year 1. He didn't fit in, he left the classroom, yelled and cursed without end, talked and talked, didn't let the teacher teach. I knew that I had to fight for him.

A few mothers found a solution to the problem by turning to the Ministry of Education or to organisations that help families whose children have difficulties assimilating within the education system:

I asked the Israel TS Organisation to come to the school and lecture the teachers on the phenomenon. I turned to the Special Education Service and asked for a teaching assistant to be assigned to him.

The more severe the case, the more mothers reported on the authorities' inability to help them, despite their appeals to different associations. The education system very often asserted that they were unable to cope with the difficulties engendered by the TS condition:

At that time, he had a lot of temper tantrums, cursing fits and yelling, and talking incessantly. He kept repeating the word 'sex'. Every sentence and in every situation, he said 'sex'... Every time the teacher couldn't cope with him, she would ask the assistant to take him out into the yard. At the end of the year, they asked him to leave the school.

Despite the fact that some of the children were diagnosed as having behavioural problems and not as 'learning disabled', it was often reported that the school decided not to deal with the situation: 
He doesn't have a learning disability. When he is calm he is very smart and fits in well. Because of his attention and hyperactivity problems, he couldn't learn and the school system just gave up.

Mothers reported that they could not trust the school because they would always call and ask them to come and take their child home or they would call to complain about the child: 'They call from school all the time. Sometimes I need to go and bring him home.'

For this reason, some mothers have to leave or change their place of work: 'I work here at home because I need to be available.' mothers spend time at school because they worry about their child being expelled from school: 'Most of the time either I or my husband was at school. It was very difficult.'

According to the evidence, the lack of appropriate services from the education system made it difficult for the family to function and in most cases, they ask the family to solve the problem by themselves:

They asked us to find another school for him, and said that he was not suited to stay in the school. With great difficulty, we found an open school and he was accepted, he cursed a child and called him 'dirty Ethiopian'. The child was the son of the therapist in the school, and they called and said they could not keep him because of his cursing [the mother began to cry]. We didn't know what to do.

Mothers felt that they need to advocate for the child opposite the education system:

I turned to the Regional and Town Support Centre which is a professional centre that provides care to children with academic difficulties in the regular education system, and asked for an assistant to stay with him. If I had not gone directly to the supervisors in the education system and the support centre, the school would have thrown him out, and he'd be in special education in a school for disturbed children.

According to the evidence, the research indicated that the main need for mothers is to receive truthful, accurate and comprehensive 
information from professionals concerning the nature of TS and its implications. Accurate information about the syndrome at the early stages of diagnosis can apparently prevent mothers from acting inappropriately or even violently towards their children with TS in order to 'discipline' them, and allow better understanding of the child's situation. Mothers blamed themselves for many years for their violent behavior towards their children with TS, and felt that they were 'not good' Mothers. However, when parents received accurate information about the syndrome, it helped them to organize their priorities correctly, and understand that what was really important was to provide the help that the child with TS needs. Additionally, having accurate information apparently helped the parents to stand up more forcefully to their extended family and friends when they needed to deal with prejudices regarding their child with TS. If explanations did not help and grandparents and aunts and uncles did not change their attitude concerning the behavior of the child with TS, the parents at least felt more comfortable after they knew the facts about the syndrome and what should be done to help the child, even if it meant distancing themselves from extended family and friends.

Once they had accurate information about the syndrome, most mothers seemed able to maintain a balance in the family and could provide explanation and support to the other children. Mothers felt that they would also be able to plan their child's treatment at the early stages of the emergence of the symptoms if they had the proper information.

Knowledge of the symptoms of the syndrome at an earlier stage could guide the mothers' reactions towards their children, and if this were successful they would be able to perceive themselves as successful mothers, and this would help them serve as a better and more positive example to their other children.

As it was, the mothers often lacked sufficient information and support, and it was found that mothers felt that they neglected their other children and were unable to fix this. They were often not sensitive enough towards the other siblings, and did not share their 
emotions or information with them. When they were given accurate information, they seemed to be more able to explain the syndrome to their other children and thus prevent misunderstandings, and consequent unpleasant situations and confusion among their children in all areas relating to the syndrome. Siblings did not have to speculate regarding the nature of the problem their brother or sister had. They did not feel so ashamed when facing their friends, and they did not unnecessarily fear that the difficulties of their sibling with TS indicated that the child was going to die. Transmission of accurate information to siblings opens channels for better communication and cooperation and thus decreases unnecessary stress.

It appeared that mothers who have a child with TS, cooperation between the parents seems to be critical. A child with TS needs much attention, as well as medical and psychiatric treatment. Most of the time, he or she needs to be accompanied at school and outside the house. Mothers of children with TS face many challenges in raising a child with TS. Therefore, cooperation between them could decrease stress and tension, employing open conversations that could prevent feelings of isolation. Cooperation between family members, meant that there was an effective division of roles between them and that the burden did not fall only mothers. Such a relationship apparently sustained mothers and enabled them to deal with the day-to-day stresses, providing tools to decrease tension. It seems that when there is adequate cooperation, mothers do not feel so exhausted and have more time and energy to give attention to the other children in the family, and siblings do not feel neglected.

In addition, it seems to be essential for mothers to have accurate information about the syndrome so that they can act as advocates for their children when facing teachers and other professionals who work in the educational system and have relations with their child with TS. In order that these professionals can help the child with TS to integrate and function within the education system, they need to be sensitive to the difficulties of the child. The findings of the present research show that in most cases the professional functionaries 
of the education system give up and send the child with TS home, leaving him or her without any educational solution. When advocating for their child with TS, it appears that the mothers must be equipped with relevant knowledge so that professionals and decision makers in the educational system can also understand the problem better and be more willing to deal with the difficulties. In this case, it would be easier if the professional bodies involved could see the child with TS as a child who needs emotional, behavioral and sometimes academic support.

The educational framework was found to be the most influential variable affecting mothers' QOL of children with TS. Mothers expressed their dissatisfaction with the educational framework, but also expressed hope that if the educational system could learn to deal with the child with TS, then there would be an improvement in their QOL.

\section{Recommendations}

The conclusions that emerged from this study seem to allow the advancement of several recommendations that can serve as a framework OR model to help mothers, educators and therapists cope more effectively with the difficulties of a child with TS. Lack of accurate diagnosis and information may lead to a state of imbalance and great stress for mothers. Professionals should understand that their role is very critical to these and that inaccurate diagnoses or the lack of any diagnosis at all leaves mothers, with a feeling of helplessness when dealing with the misunderstood behavior of their child with TS.

Additionally, the educational framework seems to avoid and reject any attempt to understand the important role it plays in the lives of these families. In the Israeli reality, children with TS are not defined as children with special needs. This research indicates that children diagnosed as having TS need to be included within this special group in order to receive appropriate educational and ther- 
apeutic assistance. Inclusion within this definition would help to improve the Mothers' QOL of those. This research offers this knowledge as a recommendation for government education policy in Israel.

The results that emerged from this research also have implications for the policy of the Ministry of Health. It is recommended that family doctors and pediatricians receive training to raise their awareness and knowledge regarding children with TS in order to avoid parents' exhausting searches for accurate diagnoses and advice and medical treatment with the consequent saving of the family's financial resources. Evidently, the need to constantly supervise the child with TS in order to prevent unsafe behavior meant that mothers often neglected the child's siblings. Families ceased their activities outside the home because they did not want to hear the comments of neighbors and friends. It is recommended that awareness towards TS should be raised amongst the community through the social services in order to avoid ignorance regarding this syndrome. Advocacy should not be the exclusive realm of the mothers, but should also be employed by professionals, who can explain the syndrome and assist the education system in its work with children with TS.

\section{References}

Abbeduto L. et al., Psychological Well-Being and Coping in Mothers of Youths with Autism, Down Syndrome, or Fragile X Syndrome. American Journal on Mental Retardation, 2004, 109, p. 237-254.

Abelson J.F. et al., Sequence Variants in Slitrk1 are Associated with Tourette's Syndrome, Science, 2005, 310(5746), p. 317-320.

Albin R.L., Mink J.W., Recent Advances in TS research. Trends Neuroscience, 2006, 293, p. 175-182.

Bowen, M., Family Therapy in Clinical Practice. Jason Ahronson, Northvale, NJ, 1978.

Brown I. et al., FQOL: Canadian Results from an International Study. Journal of Developmental and Physical Disabilities, 2003, 153, p. 209-230.

Calman K.C., Quality of Life in Cancer Patients: An Hypothesis. Journal of Medical Ethics, 1984, 10, p. 124-127. 
Carter D.A. et al., Social and Emotional Adjustment in Children Affected with Gilles De La Tourette's Syndrome: Associations with ADHD and Family Functioning. Journal of Child Psychology and Psychiatry and Allied Disciplines, 2000, 41, p. 215-223.

Diener E., Lucas R.E. (1997), Personality and Subjective Wellbeing, [in:] Hedonic psychology: Scientific perspectives on enjoyment. suffering and well-being. eds D. Kahneman, E. Diener, N. Schearz, Russell Sage Foundations, New York, 1997.

Dreher N. What is Tourette Syndrome? Current Health, 1997, 23, p. 21.

Duvdevani A., Hovav M., Rimmerman A., Ramot A., Parenting and developmental disability in Israel, Magnus Press, Jerusalem 1997.

Ganos C., Bongert J., Asmuss L. et al., The Somatotopy Of Tic Inhibition: Where and How Much? Mov Disord. 2015, 5(9), p. 1184-1189.

Garcia S.B., Perez A.M., Ortiz A.A., Mexican-American Mothers' Beliefs about Disabilities: Implications for Early Childhood Intervention. Remedial \& Special Education, 2000, 21, p. 90-102.

Greene R.W., The explosive child: A new approach for understanding and parenting easily frustrated chronically inflexible children. New York, NY, 1996. Available from the Tourette Syndrome Association, Inc. 42-40 Bell Blvd., Suite 205 Bayside, NY 11361-2820.

Haerle T., ed. Children with TS: A parent's guide. Woodbine House, Rockville, MD, 1992.

Halpern A.S., Quality of Life and Conceptual Framework for Evaluating Transition Outcomes. Exceptional Children, 1993, 596, pp. 486-498.

Kersh J., Hedvat T.T., Hauser-Cram P., Warfield M.E., The Contribution of Marital Quality to The Well-Being of Parents of Children with Developmental Disabilities. Journal of Intellectual Disability Research, 2006, 50, p. 883-893.

Kreppner K., Lerner R., Family systems and the Life Span Development: Issues and Perspectives, [in:] Family Systems and Life-Span Development. eds. K. Kreppner, R. Lerner, Laurence Erlbaum, Hillsdale, New Jersey, 1989.

Matsuda N. et al. Self-Initiated Coping with Tourette's Syndrome: Effect of Tic Suppression on QOL. Brain Development, 2016, 38(2), p. 233-41.

Pavot W., Diener E., Review of Satisfaction with Life. Psychological Assessment, 1993, 5(2), p. 164-172.

Piacentini J., Bergman R.L., Keller M., McCracken J.T., Functional Impairment in Children and Adolescents with Obsessive-Compulsive Disorder. Journal of Child and Adolescent Psychopharmacology, 2003, 13, Supplement 1, p. 61-69.

Olsson M.B., Hwang C.P. (2001) Depression in Mothers and Fathers of Children with Intellectual Disability. Journal of Intellectual Disability Research, 2001, 45, p. 535-543.

Oppenheim A. (1992), Questionnaire Design, Interviewing and Attitude Measurement, Pinter, London 1992. 
Ouellette-Kuntz H., McCreary B., Quality of Life Assessment for Persons with Severe Developmental Disabilities, [in:] Quality of Life in Health Promotion and Rehabilitation. eds. R. Renwick, I. Brown, M. Nagler, Sage Publications, Thousand Oaks, CA, 1996, p. 268-278.

Ortiz D., Greene J., Research Design: Qualitative, Quantitative and Mixed Methods Approaches. Book Review on line. Qualitative Research Journal, 2007, 6(2), p. 205-207.

Quality of Life Research Unit, An overview of the Quality of Life Research Unit, University of Toronto. Department of Occupational Therapy Centre for Function and Well-Being, University of Toronto 2001. Available at: http:/ / www.utoronto.ca/ qol/unit.htm (accessed: 1.6.2010).

Rapoport R., Rapoport R.N. (1969), The Dual Career Family: A Variant Pattern and Social Change. Human Relations, 1969, 22(1), pp. 3-30.

Ricci L.A., Hodapp R.M. (2003), Fathers of Children with Down's Syndrome Versus Other Types of Intellectual Disability: Perceptions, Stress, and Involvement. Journal of Intellectual Disability Research, 2003, 47, p. 273-284.

Robertson M., Baron-Cohen S. (1995), Tourette syndrome: The facts. Oxford University Press, Oxford 1995.

Robertson M.M., Trimble M.R., Lees A.J., The Psychopathology of the Gilles De La Tourette Syndrome. British Journal of Psychiatry, 1988, 152, pp. 383-390.

Robertson M.M., Tourette Syndrome, Associated Conditions and the Complexity of Treatment. Brain, 2002, 123, p. 425-462.

Ryan S.D., Gates M.S., Inclusion of Social Subsystem Issues in IT Investment Decisions: An Empirical Assessment. Information Resources Management Journal, 2004, $17(1)$, p. 1-18.

Shimberg E.F. (1995), Living with Tourette Syndrome. Simon and Shuster, N.Y., 1995.

Swain J., Scahill L., Lombroso P., King R., Leckman J., Tourette Syndrome and Tic Disorders: A Decade of Progress. Journal of the American Academy of Child and Adolescent Psychiatry, 2007, 46(8), p. 947-968.

Wanless R.L., Fortier L.M., Family Crisis Following the Diagnosis of a Handicapped Child, [in:] Parenting and developmental disability in Israel, eds. A. Duvdevani, M. Hovav, A. Rimmerman, Ramot, Parenting and developmental disability in Israel. Jerusalem: Y. L. Magness Pres, 1997. 